\title{
Environmental drivers of herring growth and how the perception shifts with time series length
}

\author{
Marion Claireaux, Fabian Zimmermann, Bruno Ernande, Mikko Heino, and Katja Enberg
}

\begin{abstract}
Growth is a key component of population dynamics and, thus, fisheries management, yet drivers of its variations are often poorly understood. Using individual data collected over 80 years, we explored how environmental drivers affect growth in a major population of Atlantic herring (Clupea harengus). The results confirm that intrinsic factors (age and maturation) determine growth to a large degree but also that extrinsic factors such as temperature have some influence. While the role of intrinsic factors was independent of time series length, the importance of extrinsic drivers varies strongly with the analysed time period. It remains unclear whether this is caused by data inconsistencies back in time, spurious correlations appearing in shorter time series, shifts in population dynamics, or dynamic interactions between variables that cannot be determined with current data. Generally, environmental effects on growth became less clear and relevant with increasing time series length. What drives variation in growth may therefore change over time, potentially due to impacts such as fishing or climate change. It also underlines that seemingly clear correlations can break down or change their sign over time; hence, caution is advised when interpreting results from time series of 20-40 years.
\end{abstract}

Résumé : Si la croissance est une composante clé de la dynamique des populations et, donc, de la gestion des pêches, les facteurs de variation de la croissance demeurent souvent mal compris. En utilisant des données individuelles recueillies sur plus de 80 ans, nous examinons l'incidence de facteurs environnementaux sur la croissance dans une importante population de hareng de l'Atlantique (Clupea harengus). Les résultats confirment que la croissance est en bonne partie déterminée par des facteurs intrinsèques (l'âge et la maturation), mais que des facteurs extrinsèques, comme la température, exercent aussi une certaine influence. Si le rôle des facteurs intrinsèques s'avère indépendant de la durée de la série chronologique, l'importance des facteurs extrinsèques varie considérablement selon la période analysée. Il n'est pas encore possible d'établir si ce phénomène est causé par des incohérences dans les données au fil du temps, des corrélations factices ressortant de séries chronologiques plus courtes, des changements dans la dynamique de la population ou des interactions dynamiques de variables que les données actuelles ne permettent pas de faire ressortir. En général, plus la série chronologique est longue, moins les effets environnementaux sur la croissance sont évidents et pertinents. Il est donc possible que les causes de variations de la croissance changent au fil du temps, potentiellement en raison d'impacts comme la pêche ou les changements climatiques. Cela souligne également le fait que des corrélations en apparence claires peuvent disparaître ou changer de signe au fil du temps, la prudence étant donc de mise au moment d'interpréter les résultats découlant de séries chronologiques de $20-40$ années. [Traduit par la Rédaction]

\section{Introduction}

Somatic growth of all organisms is governed by evolutionary lifehistory adaptations (Hillesheim and Stearns 1992; Enberg et al. 2012) and plastic responses to environmental conditions. Plasticity in growth emerges, among others, from resource availability per capita and is thus the combined result of ecosystem productivity and population densities. In fish, growth is typically indeterminate and is therefore subject to environmental drivers over the entire lifespan, often manifesting itself as density-dependent growth (Lorenzen and Enberg 2002; Zimmermann et al. 2018). Physical properties of the environment are also important. For example, temperature directly affects metabolic rates leading to changes in energy requirements and, indirectly, growth (Clarke and Johnston 1999). Additionally, temperature, wind, water circulation and mixing are key determinants of ecosystem productivity (e.g., Hamre 1994; Saetre and Skjoldal 2004), affecting growth through food availability.

In teleost fish, body growth manifests itself in hard parts such as otoliths or scales as ring-like structures corresponding to seasonal growth increments. These increments reveal the age and growth history of an individual fish, the use of which is comparable

Received 22 June 2021. Accepted 2 January 2022.

M. Claireaux. Institute of Marine Research, N-5817 Bergen, Norway; Department of Biological Sciences, University of Bergen, N-5020 Bergen, Norway. F. Zimmermann. Institute of Marine Research, N-5817 Bergen, Norway.

B. Ernande. MARBEC, Univ. Montpellier, Ifremer, CNRS, IRD, Montpellier, France; International Institute for Applied Systems Analysis (IIASA), A-2361 Laxenburg, Austria.

M. Heino. Institute of Marine Research, N-5817 Bergen, Norway; Department of Biological Sciences, University of Bergen, N-5020 Bergen, Norway; International Institute for Applied Systems Analysis (IIASA), A-2361 Laxenburg, Austria.

K. Enberg.* Department of Biological Sciences, University of Bergen, N-5020 Bergen, Norway.

Corresponding author: Katja Enberg (email: katja.enberg@uib.no).

*Katja Enberg served as an Associate Editor at the time of manuscript review and acceptance; peer review and editorial decisions regarding this manuscript were handled by Hui Liu.

() 2022 The Author(s). This work is licensed under a Creative Commons Attribution 4.0 International License (CC BY 4.0), which permits unrestricted use, distribution, and reproduction in any medium, provided the original author(s) and source are credited. 
to dendrochronology in trees and has been termed sclerochronology (e.g., Cyterski and Spangler 1996). The size of growth increments in these hard structures is strongly correlated with changes in body size (Black et al. 2019; Doubleday et al. 2015; Harvey et al. 2000; Rijnsdorp et al. 1990), and otoliths and scales are routinely used in fisheries research to age individual fish (Panfili et al. 2002; Pannella 1974) and back-calculate their past size-at-age (Lee 1920; Vigliola and Meekan 2009). Scales and otoliths have been collected in many commercially harvested fish stocks extensively for decades, providing some of the best-documented and longest available time series to reconstruct historic growth dynamics (Martino et al. 2019; Rijnsdorp and Van Leeuwen 1992; van der Sleen et al. 2018). Even though the relationship between the growth of hard structures and that of the somatic body can sometimes become decoupled (Mugiya and Tanaka 1992; Wright et al. 1990), growth-increment chronologies are valuable for understanding relationships between climatic variables and somatic growth at the population level (Black et al. 2013).

Norwegian spring-spawning (NSS) herring (Clupea harengus) is one of the largest fish stocks in the Atlantic Ocean, with substantial economic and ecological value. It has an extraordinary long history of commercial fishing and scientific data collection, dating back more than a century. Environmental factors govern the large-scale variations of its population dynamics (Dragesund et al.1980; Garcia et al. 2021; Trochta et al. 2020) and are assumed to cause most of the year-to-year variation in somatic growth (Ottersen and Loeng 2000). Subsequent changes in size-at-age can affect a wide range of traits such as migration potential (Slotte and Fiksen 2000), optimal swimming speed (Ware 1975, 1978), metabolic rate (Kiørboe et al. 1987) and investment in reproduction (Claireaux et al. 2021; Engelhard and Heino 2004a). A combination of overfishing and poor recruitment caused the stock to collapse in the late 1960s, leading to a decrease in the spawning stock biomass from over 3 million to a low point of around 16 thousand tonnes in 1972 (Dragesund et al.1997; Fiksen and Slotte 2002; Toresen and Østvedt 2000). Despite the subsequent fishing moratorium, it took around 15 years for the stock to recover following an exceptionally strong year class of 1983. Although variation in growth has been linked to stock density and identified as a potential management issue (ICES 2018b), density-dependent growth is to date not considered in the management strategy.

Somatic growth is the product of ecophysiological constraints, individual life-history strategies and environmentally induced plasticity, and tends to decrease with age. It can therefore be challenging to describe this trait comprehensively and disentangle the different intrinsic and extrinsic effects that cause changes over time. Mixed-effect models offer a powerful and suitable solution to model fish growth (Weisberg et al. 2010), especially by nesting repeated measurements within the specific cohort and age of each individual and capturing unaccounted temporal dynamics as random effects (Morrongiello and Thresher 2015). Advances in statistical techniques and computational power can, however, not overcome fundamental challenges in studying growth that are linked to data limitations. This includes both potential bias due to small sample sizes (Smoliński et al. 2020) as well as comparatively short time series of growth data or potential covariates. The latter has often lead to correlations breaking down or changing the sign when more data are added over time, hinting at spurious correlations or changes in population dynamics.

Utilizing a long and extensive time series of individual-level, age-specific growth increments of NSS herring that covers the period between 1935 and 2014, we tested two hypotheses: (1) somatic growth dynamics in the NSS herring are linked to conspecific density and the environment, and (2) the drivers of growth remain consistent independent of time series length. The data were analyzed with linear mixed-effect models that included different sets of fixed and random effects, and the most suitable model was selected using $\mathrm{AIC}_{\mathrm{c}}$. We explored both intrinsic and extrinsic covariates that are assumed to play a relevant role in growth, representing both density-dependent and environmental processes. The large data set enabled us to explore how extending temporal coverage affects the results, elucidating whether our perception of the drivers of somatic growth depends on the length of the time series.

\section{Materials and methods}

\section{Data description}

We used a combination of survey and catch data collected by the Institute of Marine Research from 1940 to 2014 on the Norwegian coast, Norwegian Sea and Barents Sea. The data were first inspected visually and outliers that were clearly false were removed. The geographical boundary was set to $58^{\circ} \mathrm{N}$, the southern limit of NSS herring. For each of the selected individuals, scale increment sizes (see Engelhard et al. 2003 for a brief description of the scale reading procedure) and common biometric measurements such as sex, length and weight were available. Age at capture was read from the scales and, as scale growth is a good proxy for body growth, agespecific scale increment size was used as a proxy for individual body growth (Fig. 1). The data cover consistently all cohorts within the entire time series and reflect therefore the change in age-specific growth over time (Fig. 2). However, sampling locations (Supplementary Fig. S1 ${ }^{1}$ ) and sample sizes (Supplementary Fig. S2 ${ }^{1}$ ) vary over time due to changes in sampling procedures and large fluctuations in stock distribution and cohort abundance. Accordingly, there was also a shift in the source of samples: until 1975 almost all samples were provided by commercial vessels while in the following decades most samples originated from scientific surveys (Supplementary Fig. S3 ${ }^{1}$ ). This is also reflected in a shift in the fishing gear that was used to catch the samples from mostly purse seiners to pelagic trawls commonly used on scientific surveys (Supplementary Fig. S4 ${ }^{1}$ ). We excluded cohorts with less than 10 individuals to avoid bias linked to small sample size. This analysis is based on the same database as used in Claireaux et al. (2021).

Juvenile NSS herring are spatially segregated from the adult population, with juveniles living in the Barents Sea, whereas mature individuals migrate between their feeding, overwintering and spawning grounds in the Norwegian Sea and along the coast of Norway. Our data are representative of the spawning stock, but especially before and during the collapse the sampling of the juvenile stock has been less consistent, potentially making the data on juvenile herring less representative. Furthermore, scale increments become difficult to read above age 9 , and age at capture is less reliably assessed for individuals caught after that age. We ran the analyses using scales collected from mature individuals only, captured between ages 4 and 9. Each individual carries in their scales the growth history from the start of their life, and we consequently used all the scale increment measurements available for each individual. The number of increments per individual depends on the age at capture (Fig. 1). An individual caught at age 4 years has four growth increments (from 0 to 1 , from 1 to 2 , from 2 to 3 , and from 3 to 4 years of age); thus, the number of growth increments we could use per individual was the same as the age at capture. This resulted in a sub-sample of 217627 fish and 1202814 scale increment size datapoints (see Fig. 1 for the number of increments per age and the average cumulative increment size).

Somatic growth can be influenced by a wide range of intrinsic and extrinsic variables. Here we considered intrinsic variables as those that are directly linked to the individual fish, represented by age at increment formation, stage (juvenile or adult; based on the $A_{50}$ calculated in ICES (2018a) and Engelhard and Heino (2004b); see

${ }^{1}$ Supplementary data are available with the article at https://doi.org/10.1139/cjfas-2021-0176. 
Fig. 1 (a) Cumulative scale increment size-at-age (upper green dots and line) and increment size for each age (lower blue dots and line). Note the logarithmic $y$ axis. The size of the dot corresponds to the sample size (scale shown in the legend). (b) The depiction of herring scale on the right illustrates absolute and cumulative increment size, using age 4 as an example. [Colour online.]

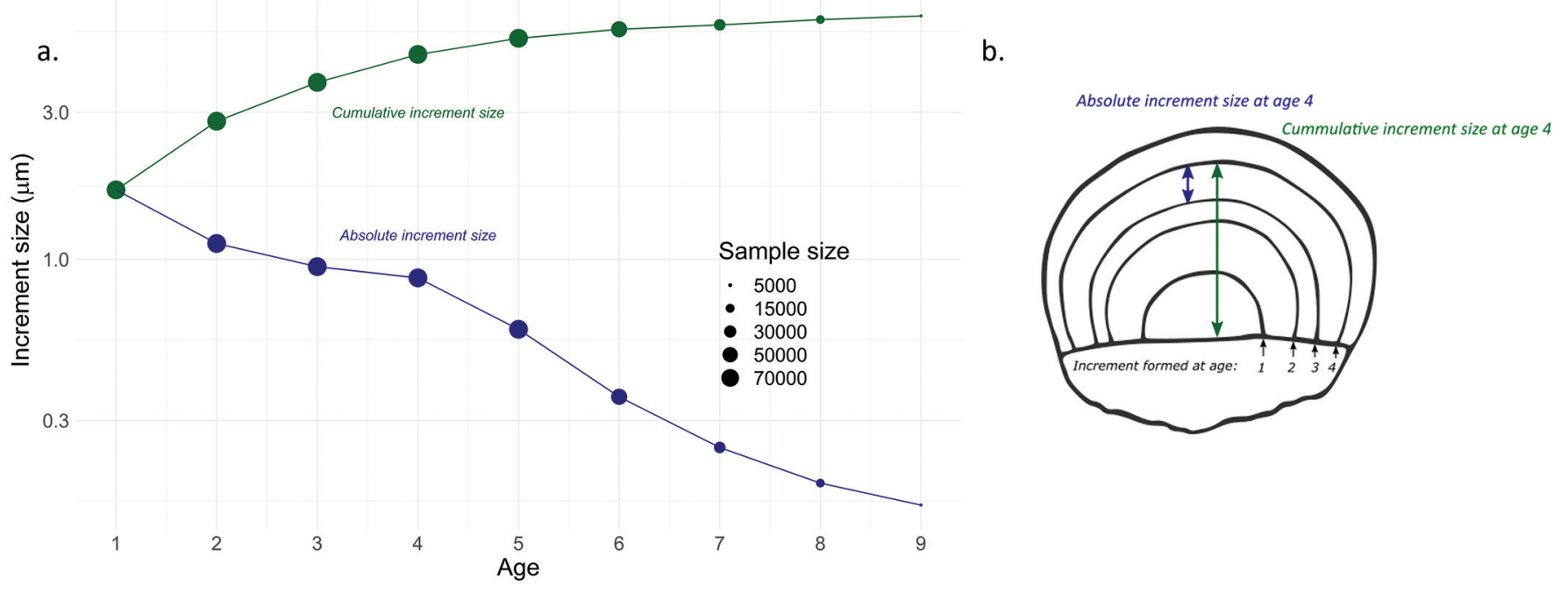

Fig. 2. Mean scale increment size by age (dots) over time with corresponding standard deviations (shaded areas). Note the logarithmic $y$ axis. [Colour online.]

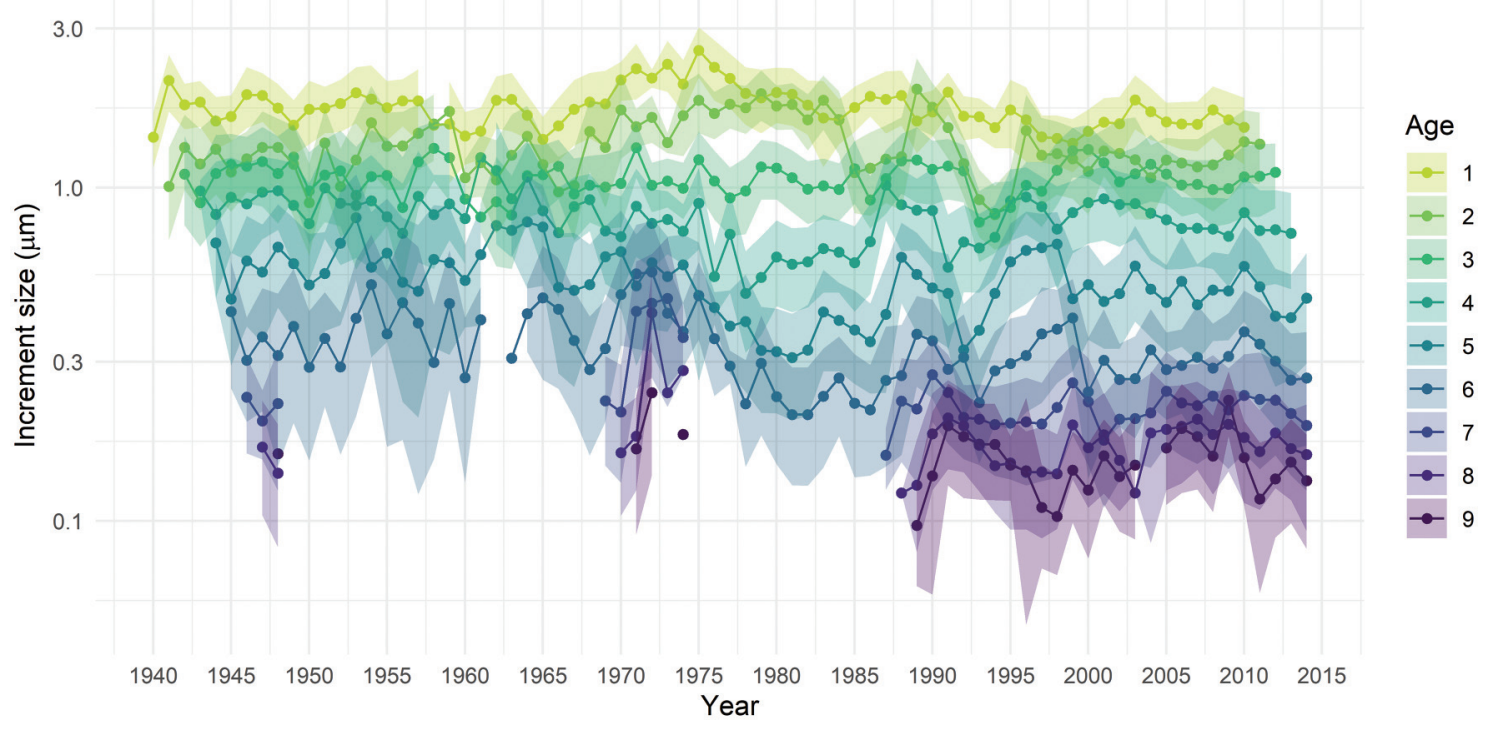

Table 1 for details) and age at capture. Extrinsic factors represent the influence of the population and environment on herring growth, here population density, temperature, and the North Atlantic Oscillation (NAO). Population density has been shown to affect fish growth (Lorenzen and Enberg 2002; Zimmermann et al. 2018), including in pelagic fish (Olafsdottir et al. 2016). We tested if conspecific density, through eventual competition, impacts the juvenile or adult growth by using, respectively, the biomass of fish of ages 2 and 3 years and the spawning stock biomass (SSB). Temperature can directly (e.g., metabolism) and indirectly (e.g., prey availability) affect growth. As juveniles and adults of NSS herring are spatially segregated and do not experience the same environment, we used different measures of temperature for each stage: the annual mean sea surface temperature (SST) at the Kola section along $33^{\circ} 30^{\prime} \mathrm{E}$ meridian in the Barents Sea for juveniles (Tereschenko 1996; http://www.pinro.ru/) and the extended reconstructed sea surface temperature (SST, Huang et al. 2015) in the Norwegian Sea during the feeding season (May to August) for adults. Besides temperature, large-scale atmospheric oscillations are known as major drivers of oceanic circulation that determine ecosystem productivity and, thus, food availability in the North Atlantic (Hátún et al. 2016; Skjoldal et al. 2004). NAO is particularly well-known as a key indicator of environmental variability with an empirically reconstructed time series of more than 100 years (National Center for Atmospheric Research 2017; Stenseth et al. 2003) and was therefore selected for our study. Table 1 provides a more detailed description of all variables used.

In addition to the listed intrinsic and extrinsic effects, variation in growth can be potentially explained by unknown properties that are inherent to each individual fish, its cohort, or the specific year. To account for this variation, we included - as random effects - an individual identifier for each fish to account for 
Table 1. Overview of all the variables included in the statistical analysis for the purpose of model selection.

\begin{tabular}{|c|c|}
\hline Parameter & Description \\
\hline \multicolumn{2}{|l|}{ Fixed effects } \\
\hline \multicolumn{2}{|l|}{ Intrinsic } \\
\hline Age & Age at which the scale increment was formed. \\
\hline Age at capture & $\begin{array}{l}\text { Age at which the fish was caught. This was included to control for potential bias due to sampling method as well as a proxy } \\
\text { for potential selectivity on growth. }\end{array}$ \\
\hline Temperature & For adults: SST of the Norwegian Sea during the feeding season (May to August). \\
\hline \multirow[t]{2}{*}{ Density } & For juveniles: the biomass of NSS herring aged 2 and 3 years old. \\
\hline & For adults: NSS herring spawning stock biomass (SSB). \\
\hline NAO & North Atlantic Oscillation in spring (March to May). \\
\hline
\end{tabular}

\section{Random effects}

Fish ID

Cohort

Year

Age
Fish unique identifier: random intercept capturing interindividual differences in growth.

Year the fish was spawned: random intercept to represent factors influencing growth occurring in early life and common to fish spawned at the same time.

Year of scale increment formation: random intercept to capture yearly variations in growth that are not explained by our fixed effects.

Random age slope tested for each random intercept above.

Note: SST, sea surface temperature; NSS herring, Norwegian spring-spawning herring.

individual differences not captured by the previous variables, as well as cohort and year to represent changes in growth that cannot be explained otherwise.

\section{Statistical models}

Linear mixed models offer a powerful method to investigate changes in growth. Growth increments at age are repeated (or nested) measures within a fish and thus correlated within individuals, and individuals born the same year are themselves nested within cohorts and likely to have correlated growth. Likewise, growth increments of different fish formed the same year are likely to be more similar than those formed in different years. Statistical analyses were run in the R software (R Core Team 2021) using the lme4 (Bates and Maechler 2010) and tidyverse (Wickham et al. 2019) packages.

We first selected the model structure for the random effects. Our set of explanatory variables was divided in intrinsic and extrinsic effects following the method used by Morrongiello and Thresher (2015; Table 1). We started with a model including the continuous variables age and age at capture and the categorical variables maturity stage (immature or mature) as the intrinsic fixed effects, the potential interactions between age or age at capture with maturity stage, and a random intercept for fish ID. All continuous fixed effects were normalized $\left(x_{\text {normalized }}=\left(x-\mu_{x}\right) / \sigma_{x}\right.$, with $\mu_{x}$ and $\sigma_{x}$ as the mean and standard deviation of the covariate, respectively) to avoid numerical fitting problems and to facilitate comparability of effect sizes. We conducted a forward selection of the random effects, progressively adding fish ID, year and cohort as random intercepts, comparing how their combined inclusion affected the model performance. In addition, we tested the inclusion of a random age slope for year. All models were fitted with REML and the Nelder-Mead optimizer (Bates et al. 2015). Following the protocol from Morrongiello and Thresher (2015; see their work for a detailed description), we used $\mathrm{AIC}_{\mathrm{c}}$ to find the model with the best random effect structure:

$$
\begin{aligned}
\log \left(G_{i, a, y}\right)=\beta_{0}+b_{0, i}+\beta_{1} a_{i}+b_{1, y} a_{i}+\beta_{2, s_{a, i}}+\beta_{3, s_{a, i}} a_{i} \\
+\beta_{4} a_{\max , i}
\end{aligned}
$$

with $G$ as growth increment of fish $i$ at age $a$ in year $y$; $\beta_{0}$ as general intercept and $b_{0, i} \sim \mathrm{N}\left(0, \sigma_{I}\right)$ as random intercept for individual fish; $\beta_{1} a_{i}$ as fixed age effect (continuous), $b_{1, y} \sim \mathrm{N}\left(0, \sigma_{Y}\right)$ as random age slope for $y, \beta_{2, s_{a, i}}$ as fixed maturity stage effect (factor), $\beta_{3, s_{a, i}} a_{i}$ as fixed interaction between maturity stage and age affect, and $\beta_{4} a_{\text {max }, i}$ as fixed age at capture effect.

We calculated the correlation among individuals within year and within cohort using the intra-class correlation coefficient (ICC). The ICC represents the proportion of variation that is explained by the grouping through the specific random effect and can be seen as a measure of growth synchrony within a year or within a cohort. The ICC was calculated for the models with only year or cohort as a random intercept, in addition to fish ID (sensu Morrongiello and Thresher (2015)).

Once the random effect structure that explained the data best (Supplementary Table $\mathrm{S}^{1}$ ) was selected, we added to eq. 1 the extrinsic fixed effects annual temperature T, NAO $N$ and density $D$ (Table 1 ) and used backward selection based on $\mathrm{AIC}_{\mathrm{c}}$ to determine the combination of fixed effects describing the data best. An interaction with stage (juvenile or adult) was included for all these variables to account for the different environments the two stages inhabit:

$$
\begin{aligned}
\log \left(G_{i, a, y}\right)= & \beta_{0}+b_{0, i}+\beta_{1} a_{i}+b_{1, y} a_{i}+\beta_{2, s_{a, i}}+\beta_{3, s_{a, i}} a_{i} \\
& +\beta_{4} a_{\max , i}+\beta_{5} T_{i}+\beta_{6, s_{a, i}} T_{i}+\beta_{7} N_{i}+\beta_{8, s_{a, i}} N_{i} \\
& +\beta_{9} D_{i}+\beta_{10, s_{a, i}} D_{i}
\end{aligned}
$$

We extracted the best linear unbiased predictor (BLUP) for the year random intercept and the age random slope to visualise interannual variations in growth that were not captured by the intrinsic and extrinsic effects we included in our model.

\section{Sensitivity to time series length}

Intensive collection of data on several intrinsic and extrinsic variables of potential relevance for NSS herring growth started in the mid-1990s, and consequently, many studies have only investigated this more recent period (e.g., dos Santos Schmidt et al. 2020). We were therefore interested in exploring how the resulting parameter estimates depend on the length of the time series used as input data. To do so, we determined the model structure that resulted in the best fit using the entire available data. This 
Table 2. Parameter estimates of the random $(a)$ and fixed $(b)$ effects of the model fitted to our entire time series (1935-2014).

\begin{tabular}{|c|c|c|c|c|c|c|c|c|}
\hline \multicolumn{9}{|c|}{ (a) Random effects } \\
\hline & Variance & SD & Correlation & & & & & \\
\hline 1|ID & 0.004 & 0.06 & - & & & & & \\
\hline 1|Year & 0.02 & 0.14 & - & & & & & \\
\hline Age|Year & 0.005 & 0.08 & 0.31 & & & & & \\
\hline Residuals & 0.08 & 0.3 & - & & & & & \\
\hline \multicolumn{9}{|l|}{ (b) Fixed effects } \\
\hline & \multicolumn{4}{|l|}{ Juveniles } & \multicolumn{4}{|l|}{ Adults } \\
\hline & Beta & SE & $t$ value & $p$ value & Beta & SE & $t$ value & $p$ value \\
\hline \multicolumn{9}{|c|}{ Intrinsic effects } \\
\hline Intercept & -0.86 & 0.02 & -15.8 & $<0.001$ & 0.17 & 0.02 & 9.0 & $<0.001$ \\
\hline Age & -0.27 & 0.009 & -30.3 & $<0.001$ & -0.45 & 0.009 & -50.9 & $<0.001$ \\
\hline Age at capture & 0.003 & 0.0002 & 13.0 & $<0.001$ & 0.003 & 0.0002 & 13.0 & $<0.001$ \\
\hline \multicolumn{9}{|c|}{ Extrinsic effects } \\
\hline Temperature & -0.048 & 0.004 & -11.2 & $<0.001$ & -0.12 & 0.004 & -29.2 & $<0.001$ \\
\hline Density & -0.003 & 0.002 & 0.006 & 0.9 & 0.0003 & 0.0009 & 0.3 & 0.76 \\
\hline NAO & -0.00009 & 0.014 & -1.63 & 0.1 & 0.08 & 0.01 & 5.27 & $<0.001$ \\
\hline
\end{tabular}

Note: Interpretation of the significance of the $p$ value should be made with caution, as the model is fitted to a very large amount of data. All parameters are unitless due to normalization.

was followed by testing the sensitivity of parameter estimates (direction, effect size and significance) to the length of the time series used by applying the model selected with the full time series to shortened time series. Implicitly, our approach also tested the robustness of the model (i.e., whether the model converges with shorter time series and, thus, less input data). These time series were built by sequentially removing sections of 10 years from the full time series, restricting the time series to 1950-2014, 1960-2014, 1970-2014, 1980-2014 and 1990-2014 compared to 1935-2014 in the complete time series. The data in all the years included were kept intact.

\section{Results}

When selecting the temporal structure of the model, we found that year was more important than cohort, as the temporal growth synchrony measured by the ICC was clearly lower across individuals from the same cohort $\left(\mathrm{ICC}_{\mathrm{c}}=0.03\right)$ than from the same year $\left(\mathrm{ICC}_{\mathrm{y}}=0.14\right)$. The model that explained the data over the whole time series 1935-2014 best based on $\mathrm{AIC}_{\mathrm{c}}$ was selected for further analysis and consisted of individual ID and year as random intercepts, and a random slope for age varying with year (Supplementary Table $S 1^{1}$ ). For the fixed effects, age, age at capture and stage were included as intrinsic fixed effects, and density, temperature and NAO as extrinsic fixed effects (Table 1). Excluding any fixed effects did not improve the model fit. The amount of variance explained by the full model was high: the proportion of variance in herring growth explained by only the fixed effects was $81 \%$ (marginal $R^{2}=0.81$ ), while the whole model explained $86 \%$ of that variance (conditional $R^{2}=0.86$; Nakagawa and Schielzeth 2013; Morrongiello and Thresher 2015).

Intrinsic effects explained a substantial part of the variation, with age as the most important variable in explaining growth for both juveniles and adults (Table 2; Fig. 3). Stage was found to be highly relevant as well, represented by statistically significant interactions with all other covariates. In addition, we found a statistically significant positive effect of age at capture ( $\beta=0.003$ (unitless due to normalization); $p<0.001$ ), but a near-negligible effect size.

The extrinsic effects (temperature, NAO and conspecific density) explained comparatively little of the overall variation, representing only a marginal improvement of the $R^{2}$. Nevertheless, SST and NAO were found to be significantly correlated with growth. Specifically, we found a negative effect of temperature on juvenile and adult growth $(\beta=-0.05 ; p<0.01$ and $\beta=-0.12 ; p<0.01$, respectively), whereas adult growth was positively correlated to NAO $(\beta=0.08 ; p<0.01)$. The effects of NAO on juvenile growth and conspecific density on both adult and juvenile growth were nonsignificant.

The random effects captured interannual variation in growth that showed no particular pattern, with the exception of a 10-year period: between 1990 and 2000 growth seemed to slow down, before reaching average levels again (Fig. 4).

\section{Sensitivity to time series length}

To investigate the effect of different time series length on the relationships between growth and intrinsic and extrinsic variables, we ran the statistical model for time series of different lengths, starting with 1990-2014, and gradually extending by steps of ten years up to the full time series, 1935-2014 (Supplementary Table S2 ${ }^{1}$; note that the statistical model did not converge when using the time series 1970-2014 and the results are therefore excluding this time series). In general, the direction and effect size of intrinsic variables (age and age at capture) on growth were largely independent of the length of the time series the model was fitted to (Fig. 3). The effects of extrinsic variables (i.e., temperature, density and NAO), on the other hand, varied with the length of the time series, which affected effect size, significance and direction of the corresponding parameter estimates. Overall, the shortest time series covering the most recent 25 years (1990-2014) showed the clearest deviations in effect size, direction and significance compared to the parameter values estimated for the entire time series (1935-2014).

The relationship between temperature and juvenile growth was highly dependent on the time series length (Fig. 3). In the time series sampled after 1980 temperature had a strong positive effect on juvenile growth, but extending the time series back in time reversed this relationship and when the whole time series was used, there was a negative relationship between temperature and juvenile growth. For the adults, growth was negatively correlated with temperature regardless of the time series length, even though in the shortest times (1990-2014) temperature had much less negative effect than in the longer time series.

The relationship between NAO and juvenile growth was close to negligible in all times series except the shortest, most recent one (1990-2014) where it was slightly negative (Fig. 3). NAO had a significantly positive correlation with adult growth in all but the most recent time series (1990-2014).

The correlation between conspecific density and growth was changing considerably depending on the time series length (Fig. 3). When only data sampled after 1980 were used, density had a strong positive effect on juvenile growth, but extending the time series 
Fig. 3. Parameter values of the fixed effects estimated by the selected linear mixed effects model fitted to the entire time series (empty circles) and shortened time series (remaining symbols) for juvenile (a) and adult $(b)$ herring. Lines indicate $95 \%$ confidence intervals (if too small, then not visible for some parameters). Full model means the whole time series from 1935 to 2014. The time series 1970-2014 had problems with model convergence and the results have been excluded. All parameters are dimensionless due to normalization. NAO, North Atlantic Oscillation.
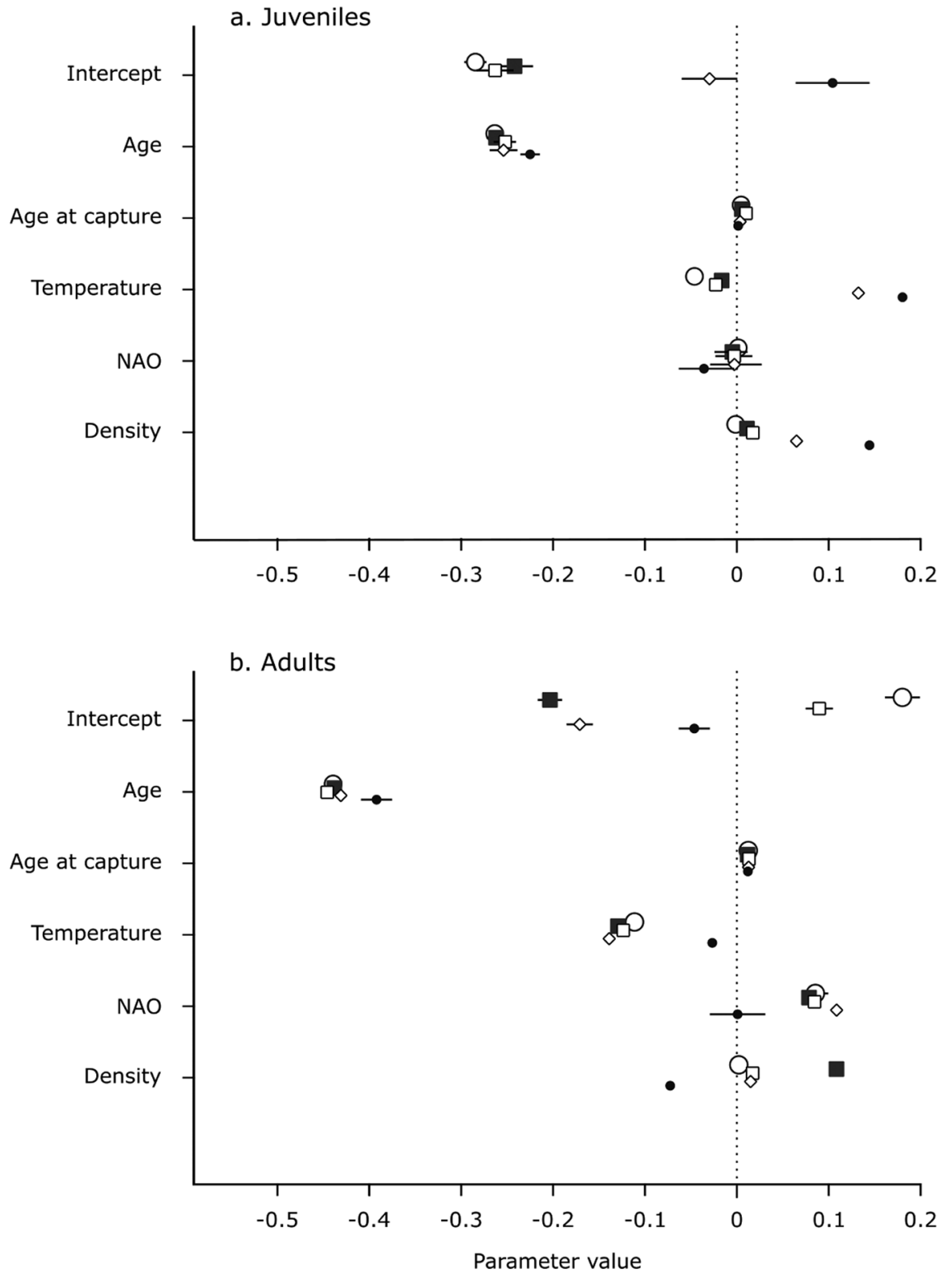

- $1950-2014$

ㅁ $1960-2014$

$\diamond 1980-2014$

- $1990-2014$

Parameter value

made this relationship negligible and nonsignificant. For adults the relationship switched between negative for the shortest time series (1990-2014) to positive for the second longest time series (1950-2014), but being negligible when the full time series (19352014) was used.

\section{Discussion}

Using an 80-year time series of individual growth measurements, we showed that a large degree of the observed variation can be explained by a combination of intrinsic and extrinsic drivers, including temperature. Age was the most important and consistent determinant of growth, underlining that growth is first and foremost an intrinsic process determined by life history, decreasing with increasing age and length. However, these variables could not explain all observed variation and a relevant proportion was found to be significantly linked to temperature and, to a minor degree, NAO, while there was no consistent correlation with conspecific density. In addition, there was remaining interannual variation represented by random effects of year on the intercept and age slope, indicating that the explanatory variables available for our study did not cover all relevant annually varying drivers of growth. The results underline the complexity of a process such as growth that is the combined product of life history and phenotypic plasticity in response to the environment (e.g., Enberg et al. 2012). Disentangling these different drivers through statistical analysis is a major challenge, as became evident in our sensitivity analysis revealing that size, direction and significance of correlations with extrinsic drivers are highly dependent of the length of the analysed time series. 
Fig. 4. The best linear unbiased predictors (BLUP) of the random intercept for year and the random age slope for year. Dots show the mean predicted value, and grey shaded areas show the $95 \%$ confidence intervals (too small to be visible for most years).

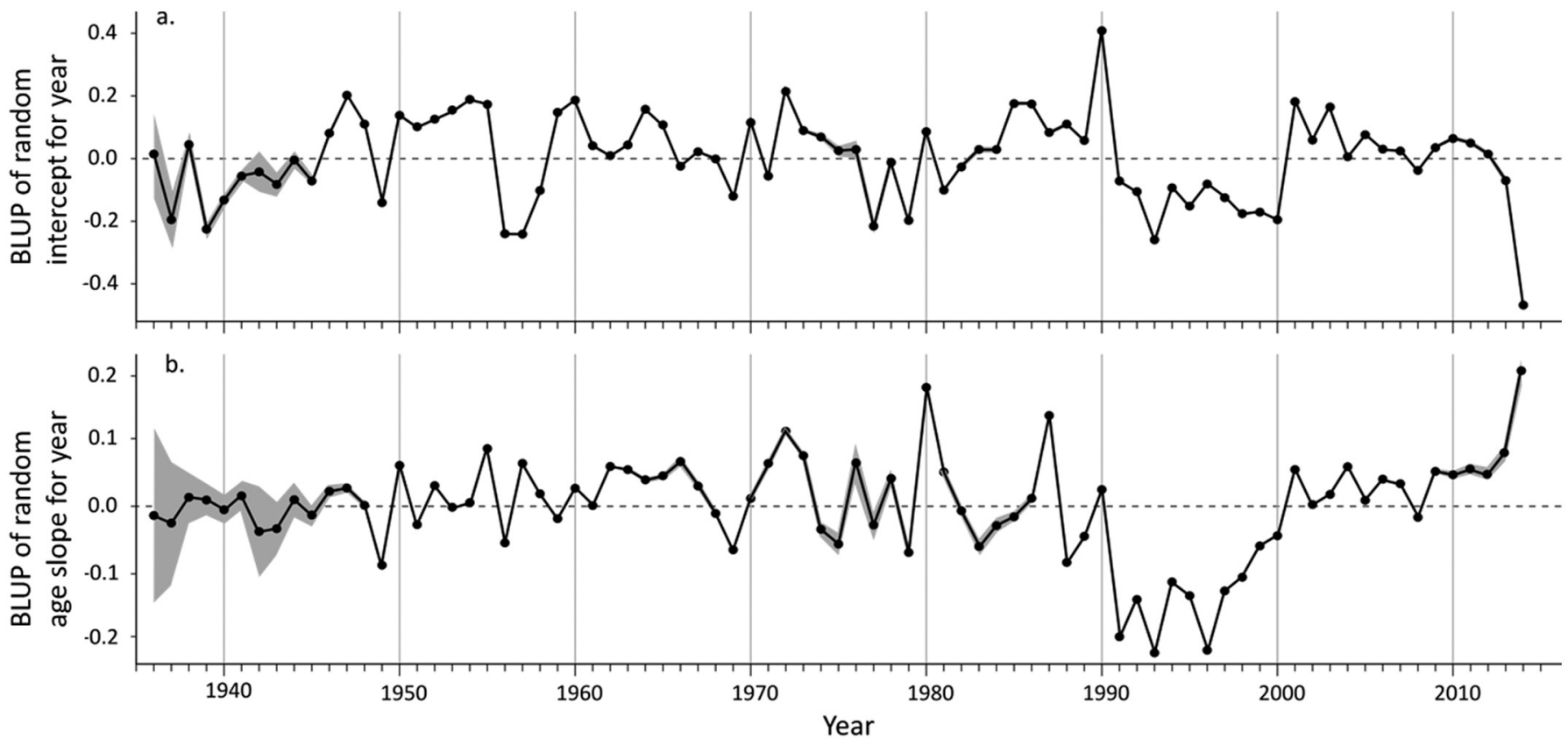

Relationships with environmental variables that change or break down over time are a well-known issue in ecology (Drinkwater et al. 2013; Hátún et al. 2016). This can be explained by spurious correlations and third variables, changing dynamics over time due to, for example, a regime shift, interactions between variables, inconsistencies in data collection over time, or a combination thereof. In marine ecology, previously established links between population dynamics and environmental drivers could often not be reproduced later on, especially for recruitment (Myers 1998), including in NSS herring (Garcia et al. 2021; Zimmermann et al. 2019). However, the cause for the deterioration of significant correlations has remained elusive. A major obstacle is the general scarcity of long time series, restricting many studies to comparatively short time series of about 20-40 years that may not cover supra-decadal environmental cycles and often include clear unidirectional trends, making them prone for type II errors. For growth this may be exacerbated by the large intrinsic effects in individual growth processes compared to the lesser effects of extrinsic drivers on overall variation (Denechaud et al. 2020a). Moreover, limited data also constrain the possibilities to explore nonstationarity over time through, for example, sensitivity or change-point analysis. Sudden or gradual changes in environmental conditions or ecosystem composition may, for instance, lead to fundamental shifts in the drivers or limiting factors of population dynamics, altering how a population responds to changes in a specific variable. Lastly, different variables may influence each other, depend on a third variable, or exert interacting effects, blurring the statistical detectability of real signals.

The NSS herring population and its environment have undergone drastic changes over the course of the 80 years study period, including the onset of industrial fishing, a population collapse in the late 1960s followed by a full recovery in 1990s, a warming trend over the past decades, and the habitat expansion of the Northeast Atlantic mackerel (Scomber scombrus) as a potential competitor and predator of herring eggs and larvae (Skaret et al. 2015; Bachiller et al. 2016; Allan et al. 2021). Considering that growth is the product of an organism's entire life history and the environment it is experiencing (Enberg et al. 2012), it is likely that NSS herring has adapted to the changes it has experienced over time. Thus, the growth dynamics of herring today may be very different from what they have been before the stock collapse. In contrast to other long-lived species, such as Atlantic cod (Gadus morhua) where there is evidence strongly suggesting evolutionary adaptations to fishing and, potentially, climate, the life-history adaptations in herring may be more subtle (Heino et al. 2015) and occur in traits that are more difficult to measure, such as behaviour (Claireaux et al. 2018) or reproductive investment (Claireaux et al. 2021). In addition, growth is linked to spatiotemporal dynamics both in the environment and the distribution of a stock. As NSS herring undertakes large migrations from overwintering and spawning areas to feeding grounds, the spatial movements over time could add relevant information about the specific environment an individual experienced. However, because only the position at capture was known, the data did not allow to trace the individual movements through time. No spatial residual patterns linked to the position at capture were observed.

Thorough model validation and sensitivity analysis can help to elucidate the robustness of statistical results when analysing large datasets and long time series. While the present study is based on an exceptionally large dataset ( $>1$ million increment size datapoints) in an ecological context where long, consistent time series of good quality are rare, its analysis also comes with specific caveats. Besides the practical challenges of handling a large data set of over a million nested data points, the large amount of data also tends to facilitate type I errors by inflating the significance of correlations. This can create the impression of relevant links to environmental drivers despite a negligible effect size, such as we observed for the effect of NAO on growth. This underlines the need for a careful evaluation of results obtained from large datasets that go beyond statistical significance, as significance may become increasingly meaningless with the large amount of data.

Long time series as the one applied here are prone to containing small changes in sampling regimes. In our data the most marked temporal change is that the data prior to 1970 mostly originates from commercial catches, while the data collected between early 1970 s and early 2000s is dominated by survey data (Supplementary Fig. $S 3^{1}$ ). We explored the sensitivity of our results to the 
data source by including the fleet type (commercial or survey) into the model, but the improvement in the model's ability to explain the patterns was very marginal at the level of $0.4 \%$ lowered AIC. In addition, including the fleet type in the model caused convergence issues, probably because of collinearity with the year effect, and the potential variation caused by changes in the annual proportion in fleet types is likely absorbed by the year effect. We therefore feel confident that the type of fleet that collected the data did not largely impact the results obtained here.

Existing studies on growth have typically been limited by the shortness of the available time series of growth information (van der Sleen et al. 2018) or the covariates used (Denechaud et al. 2020b). Good quality individual growth information from hard parts for long time periods is generally rare due to the large effort required to collect and read them. Limited resources lead, therefore, typically to small sample sizes and ageing errors that can blur the effect of environmental drivers on growth (Smoliński et al. 2020). Instead of reconstructed individual growth, many previous studies on growth dynamics in fish relied on whole-fish weight measurements at capture that are more readily available (Olafsdottir et al. 2016; Zimmermann et al. 2018). However, fish weight is heavily confounded with short-term dynamics, linked to, for example, feeding and reproduction, and typically based on one final sampling point at catch that does not allow to trace the individual growth back in time. While this may be sufficient to detect strong signals on a population level, this type of data are not suitable to study individual growth. Yet even when an adequate time series on individual growth exists, analysis may be equally constrained by the availability of data on the potential drivers of growth, as the time series are often shorter, of low resolution, low quality, or a combination thereof. This applies specifically to food availability as a likely key driver of growth, because time series on abundance of prey such as zooplankton or forage fish are often short and insufficient. As a result, information on food availability is either omitted - as in the present study - or constrains the length of the analysis time series substantially (Denechaud et al. 2020b).

Our results highlight the challenges and potential pitfalls when analyzing individual growth in fish populations. Nevertheless, understanding growth is important since growth is a crucial component of population dynamics and, thus, sustainable management of fish stocks. Growth is a key component of a fish's life history (Enberg et al. 2012) and determines size-at-age, which has been linked to reproductive potential (Barneche et al. 2018; Hixon et al. 2014) and, subsequently, the productivity and resilience of fish stocks (Berkeley et al. 2004; Francis et al. 2007; Laugen et al. 2014). The size of fish has, furthermore, also economic consequences (Zimmermann et al. 2011), underlining the relevance for traditional fisheries management. Determining the drivers of growth may therefore contribute to better predictions on the dynamics of fish stocks, both in short-term forecasts and regarding the longterm responses to fishing and climate change. Our study contributed novel findings on the drivers of growth in NSS herring and how their perception varies with increasing time series length, revealing the need for careful sensitivity analysis when studying growth.

\section{Acknowledgements}

The authors acknowledge the Research Council of Norway for funding (ConEvolHer project, No. 243735). The funders had no role in study design, data collection and analysis, decision to publish, or preparation of the manuscript.

\section{References}

Allan, B.J.M., Ray, J.L., Tiedemann, M., Komyakova, V., Vikebo, F., Skaar, K.S., et al. 2021. Quantitative molecular detection of larval Atlantic herring
(Clupea harengus) in stomach contents of Atlantic mackerel (Scomber scombrus) marks regions of predation pressure. Sci. Rep. 11: 5095. doi:10.1038/s41598021-84545-7. PMID:33658658.

Bachiller, E., Skaret, G., Nottestad, L., and Slotte, A. 2016. Feeding ecology of Northeast Atlantic Mackerel, Norwegian Spring-Spawning Herring and Blue Whiting in the Norwegian Sea. PLoS ONE, 11: e0149238. doi:10.1371/ journal.pone.0149238. PMID:26895485.

Bates, D., and Maechler, M. 2010. Linear mixed-effects models using S4 classes. $\mathrm{R}$ package version 0.999375-35.

Bates, D., Maechler, M., Bolker, B., and Walker, S. 2015. Fitting Linear Mixed-Effects Models Using \{lme4\}. J. Stat. Softw. 67(1): 1-48.

Barneche, D.R., Robertson, D.R., White, C.R., and Marshall, D.J. 2018. Fish reproductive-energy output increases disproportionately with body size. Science, 360(6389): 642-645. doi:10.1126/science.aao6868. PMID:29748282.

Berkeley, S.A., Hixon, M.A., Larson, R.J., and Love, M.S. 2004. Fisheries sustainability via protection of age structure and spatial distribution of fish populations. Fisheries, 29(8): 23-32. doi:10.1577/1548-8446(2004)29[23:FSVPOA] 2.0.CO;2.

Black, B.A., von Biela, V.R., Zimmerman, C.E., and Brown, R.J. 2013. Lake trout otolith chronologies as multidecadal indicators of high-latitude freshwater ecosystems. Polar Biol. 36(1): 147-153. doi:10.1007/s00300-012-1245-9.

Black, B.A., Andersson, C., Butler, P.G., Carroll, M.L., DeLong, K.L., Reynolds, D.J., et al. 2019. The revolution of crossdating in marine palaeoecology and palaeoclimatology. Biol. Lett. 15(1): 20180665. doi:10.1098/rsbl.2018.0665. PMID:30958223.

Claireaux, M., Jørgensen, C., and Enberg, K. 2018. Evolutionary effects of fishing gear on foraging behavior and life-history traits. Ecol. Evol. 8(2): 10711-10721. doi:10.1002/ece3.4482.

Claireaux, M., dos Santos Schmidt, T.C., Olsen, E.M., Slotte, A., Varpe, Ø., Heino, M., and Enberg, K. 2021. Eight decades of adaptive changes in herring reproductive investment: the joint effect of environment and exploitation. ICES J. Mar. Sci. 78: 631-639. doi:10.1093/icesjms/fsaa123.

Clarke, A., and Johnston, N.M. 1999. Scaling of metabolic rate with body mass and temperature in teleost fish. J. Anim. Ecol. 68(5): 893-905.

Cyterski, M.J., and Spangler, G.R. 1996. A tool for age determination. N. Am. J. Fish Manage. 16(2): 403-412. doi:10.1577/1548-8675(1996)016<0403:ATFAD>2.3. $\mathrm{CO} ; 2$

Denechaud, C., Smoliński, S., Geffen, A.J., and Godiksen, J.A. 2020a. Longterm temporal stability of Northeast Arctic cod (Gadus morhua) otolith morphology. ICES J. Mar. Sci. 77(3): 1043-1054. doi:10.1093/icesjms/fsz259.

Denechaud, C., Smoliński, S., Geffen, A.J., Godiksen, J.A., and Campana, S.E. $2020 \mathrm{~b}$. A century of fish growth in relation to climate change, population dynamics and exploitation. Global Change Biol. 26(10): 5661-5678. doi:10.1111/ gcb.15298. PMID:32741054

Doubleday, Z.A., Izzo, C., Haddy, J.A., Lyle, J.M., Ye, Q., and Gillanders, B.M. 2015. Long-term patterns in estuarine fish growth across two climatically divergent regions. Oecologia, 179(4): 1079-1090. doi:10.1007/s00442-0153411-6. PMID:26245148.

dos Santos Schmidt, T.C., Devine, J.A., Slotte, A., Claireaux, M., Johannessen, A., Enberg, K., et al. 2020. Environmental stressors may cause unpredicted, notably lagged life-history responses in adults of the planktivorous Atlantic herring. Prog. Oceanogr. 181: 102257. doi:10.1016/j.pocean.2019.102257.

Dragesund, O., Hamre, J., and Ulltang, Ø. 1980. Biology and population dynamics of the Norwegian spring-spawning herring. Rapp. P.-v. Reun. Cons. Int. Explor. Mer, 177: 43-71.

Dragesund, O., Johannessen, A., and Ulltang, Ø. 1997. Varlation in migration and abundance of Norwegian spring spawning herring (Clupea harengus L.). Sarsia, 82(2): 97-105. doi:10.1080/00364827.1997.10413643.

Drinkwater, K., Colbourne, E., Loeng, H., Sundby, S., and Kristiansen, T. 2013. Comparison of the atmospheric forcing and oceanographic responses between the Labrador Sea and the Norwegian and Barents seas. Prog. Oceanogr. 114(10): 11-25. doi:10.1016/j.pocean.2013.03.007.

Enberg, K., Jørgensen, C., Dunlop, E.S., Varpe, Ø., Boukal, D.S., Baulier, L., et al. 2012. Fishing induced-evolution of growth: concepts, mechanisms and the empirical evidence. Mar. Ecol. 33(1): 1-25. doi:10.1111/j.1439-0485.2011.00460.x.

Engelhard, G.H., Dieckmann, U., and Godø, O.R. 2003. Age at maturation predicted from routine scale measurements in Norwegian spring-spawning herring (Clupea harengus) using discriminant and neural network analyses. ICES J. Mar. Sci. 60(2): 304-313.

Engelhard, G.H., and Heino, M. 2004a. Maturity changes in Norwegian springspawning herring before, during, and after a major population collapse. Fish. Res. 66(2-3): 299-310. doi:10.1016/S0165-7836(03)00195-4.

Engelhard, G.H., and Heino, M. 2004b. Maturity changes in Norwegian spring-spawning herring Clupea harengus: compensatory or evolutionary responses? Mar. Ecol. Prog. Ser. 272: 245-256.

Fiksen, O., and Slotte, A. 2002. Stock-environment recruitment models for Norwegian spring spawning herring (Clupea harengus). Can. J. Fish. Aquat. Sci. 59(2): 211-217. doi:10.1139/f02-002.

Francis, R., Hixon, M., Clarke, M., Murawski, S., and Ralston, S. 2007. Ten commandments for ecosystem-based fisheries scientists. Fisheries, 32(5): 217-233. doi:10.1577/1548-8446(2007)32[217:TCFBFS]2.0.CO;2.

Garcia, T., Planque, B., Arneberg, P., Bogstad, B., Skagseth, Ø., and Tiedemann, M. 2021. An appraisal of the drivers of Norwegian spring-spawning herring (Clupea harengus) recruitment. Fish. Oceanogr. 30(2): 159-173. doi:10.1111/fog.12510. 
Hamre, J. 1994. Biodiversity and exploitation of the main fish stocks in the Norwegian - Barents Sea ecosystem. Biodivers. Conserv. 3(6): 473-492.

Harvey, J.T., Loughlin, T.R., Perez, M.A., and Oxman, D.S. 2000. Relationship between fish size and otolith length for 63 species of fishes from the eastern North Pacific Ocean. NOAA Technical Report NMFS 150. NOAA.

Hátún, H., Lohmann, K., Matei, D., Jungclaus, J.H., Pacariz, S., Bersch, M., et al 2016. An inflated subpolar gyre blows life toward the northeastern Atlantic. Prog. Oceanogr. 147: 49-66. doi:10.1016/j.pocean.2016.07.009.

Heino, M., Diaz-Pauli, B., and Dieckmann, U. 2015. Fisheries-induced evolution. Annu. Rev. Ecol. Evol. Syst. 46(1): 461-480. doi:10.1146/annurev-ecolsys-112414054339.

Hillesheim, E., and Stearns, S.C. 1992. Correlated responses in life-history traits to artificial selection for body weight in Drosophila melanogaster. Evolution, 46(3): 745-752.

Hixon, M.A., Johnson, D.W., and Sogard, S.M. 2014. BOFFFFs: on the importance of conserving old-growth age structure in fishery populations. ICES J. Mar. Sci. 71(8): 2171-2185. doi:10.1093/icesjms/fst200.

Huang, B., Banzon, V.F., Freeman, E., Lawrimore, J., Liu, W., Peterson, T.C., et al. 2015. Extended Reconstructed Sea Surface Temperature (ERSST), Version 4. NOAA National Centers for Environmental Information. doi:10.7289 V5KD1VVF.

ICES. 2018a. Report of the Working Group on Widely Distributed Stocks (WGWIDE). International Council for the Exploration of the Sea (ICES) ICES CM 2010/ACOM:15, Torshavn, Faroe Islands.

ICES. 2018b. Report of the Workshop on the determination of reference points for Norwegian Spring Spawning Herring (WKNSSHREF). Copenhagen, Denmark.

Kiørboe, T., Munk, P., and Richardson, K. 1987. Respiration and growth of larval herring Clupea harengus: relation between specific dynamic action and growth efficiency. Mar. Ecol. Prog. Ser. 40(1): 1-10. doi:10.3354/meps040001.

Laugen, A.T., Engelhard, G.H., Whitlock, R., Arlinghaus, R., Dankel, D.J., Dunlop, E.S., et al. 2014. Evolutionary impact assessment: accounting for evolutionary consequences of fishing in an ecosystem approach to fisheries management. Fish Fish. 15(1): 65-96. doi:10.1111/faf.12007.

Lee, R.M. 1920. A review of the methods of age and growth determination in fishes by means of scales. Ministry of Agriculture \& Fisheries Fishery Investigations Series 2, Vol. 4. Board of Agriculture and Fisheries.

Lorenzen, K., and Enberg, K. 2002. Density-dependent growth as a key mechanism in the regulation of fish populations: evidence from among-population comparisons. Proc. R Soc. B Biol. Sci. 269(1486): 49-54. doi:10.1098/rspb.2001. 1853. PMID:11788036.

Martino, J.C., Fowler, A.J., Doubleday, Z.A., Grammer, G.L., and Gillanders, B.M 2019. Using otolith chronologies to understand long-term trends and extrinsic drivers of growth in fisheries. Ecosphere, 10(1): e02553. doi:10.1002/ ecs2.2553.

Morrongiello, J.R., and Thresher, R.E. 2015. A statistical framework to explore ontogenetic growth variation among individuals and populations: a marine fish example. Ecol. Monogr. 85(1): 93-115. doi:10.1890/13-2355.1.

Mugiya, Y., and Tanaka, S. 1992. Otolith development, increment formation, and an uncoupling of otolith to somatic growth rates in larval and juvenile goldfish. Nippon Suisan Gakkaishi, 58(5): 845-851. doi:10.2331/suisan.58.845.

Myers, R.A. 1998. When do environment-recruitment correlations work? Rev. Fish. Biol. Fish. 8(3): 285-305. doi:10.1023/A:1008828730759.

Nakagawa, S., and Schielzeth, H. 2013. A general and simple method for obtaining $\mathrm{R}^{2}$ from generalized linear mixed-effects models. Methods Ecol. Evol. 4(2): 133-142. doi:10.1111/j.2041-210x.2012.00261.x.

National Center for Atmospheric Research. 2017. The Climate Data Guide: Hurrell North Atlantic Oscillation (NAO) Index (PC-based). Available from https://climatedataguide.ucar.edu/climate-data/hurrell-north-atlanticoscillation-nao-index-pc-based.

Olafsdottir, A.H., Slotte, A., Jacobsen, J.A., Oskarsson, G.J., Utne, K.R., and Nøttestad, L. 2016. Changes in weight-at-length and size-at-age of mature Northeast Atlantic mackerel (Scomber scombrus) from 1984 to 2013: effects of mackerel stock size and herring (Clupea harengus) stock size. ICES J. Mar. Sci. 73(4): 1255-1265. doi:10.1093/icesjms/fsv142.

Ottersen, G., and Loeng, H. 2000. Covariability in early growth and yearclass strength of Barents Sea cod, haddock, and herring: the environmental link. ICES J. Mar. Sci. 57(2): 339-348. doi:10.1006/jmsc.1999.0529.

Panfili, J., de Pontual, H., Troadec, H., and Wright, P.J. (Editors). 2002. Manual of fish sclerochronology. Ifremer, Brest, France.
Pannella, G. 1974. Otolith growth patterns: an aid in age determination in temperate and tropical fishes. In Proceedings of an International Symposium on the Ageing of Fish. Unwin Brothers. pp. 28-39.

$\mathrm{R}$ Core Team. 2021. R: A language and environment for statistical computing. R Foundation for Statistical Computing, Vienna, Austria.

Rijnsdorp, A.D., and van Leeuwen, P.I. 1992. Density-dependent and independent changes in somatic growth of female North Sea plaice Pleuronecles platessa between 1930 and 1985 as revealed by back-calculation of otoliths. Mar. Ecol. Prog. Ser. 88(1): 19-32. doi:10.3354/meps088019.

Rijnsdorp, A.D., van Leeuwen, P.I., and Visser, T.A.M. 1990. On the validity and precision of back-calculation of growth from otoliths of the plaice, Pleuronectes platessa L. Fish. Res. 9(2): 97-117. doi:10.1016/0165-7836(90)90058-4.

Skaret, G., Bachiller, E., Langøy, H., and Stenevik, E.K. 2015. Mackerel predation on herring larvae during summer feeding in the Norwegian Sea. ICES J. Mar. Sci. 72(8): 2313-2321.

Skjoldal, H.R., Sætre, R., Fernø, A., Misund, O.A., and Røttingen, I. 2004. The Norwegian Sea ecosystem. Tapir Forlag, Trondheim.

Slotte, A., and Fiksen, O. 2000. State-dependent spawning migration in Norwegian spring-spawning herring. J. Fish Biol. 56(1): 138-162. doi:10.1111/ j.1095-8649.2000.tb02091.x.

Smoliński, S., Morrongiello, J., Sleen, PVD., Black, B.A., and Campana, S.E. 2020. Potential sources of bias in the climate sensitivities of fish otolith biochronologies. Can. J. Fish. Aquat. Sci. 77(9): 1552-1563. doi:10.1139/cjfas-2019-0450.

Stenseth, N.C., Ottersen, G., Hurrell, J.W., Mysterud, A., Lima, M., Chan, K.S., et al. 2003. Studying climate effects on ecology through the use of climate indices: the North Atlantic Oscillation, El Niño Southern Oscillation and beyond. Proc. R Soc. B Biol. Sci. 270(1529): 2087-2096. doi:10.1098/rspb.2003. 2415. PMID:14561270.

Tereschenko, V.V. 1996. Seasonal and year-to-year variations of temperature and salinity along the Kola meridian transect, ICES CM. 1996/C: 11.

Toresen, R., and Østvedt, O.J. 2000. Variation in abundance of Norwegian spring-spawning herring (Clupea harengus, Clupeidae) throughout the 20th century and the influence of climatic fluctuations. Fish Fish. 1(3): 231-256. doi:10.1046/j.1467-2979.2000.00022.x.

Trochta, J.T., Branch, T.A., Shelton, A.O., and Hay, D.E. 2020. The highs and lows of herring: A meta-analysis of patterns and factors in herring collapse and recovery. Fish Fish. 21(3): 639-662. doi:10.1111/faf.12452.

van der Sleen, P., Stransky, C., Morrongiello, J.R., Haslob, H., Peharda, M., and Black, B.A. 2018. Otolith increments in European plaice (Pleuronectes platessa) reveal temperature and density-dependent effects on growth. ICES J. Mar. Sci. 75: 1655-1663. doi:10.1093/icesjms/fsy011.

Vigliola, L., and Meekan, M.G. 2009. The back-calculation of fish growth from otoliths. In Tropical fish otoliths: information for assessment, management and ecology. Springer. pp. 174-211.

Ware, D.M. 1975. Growth, metabolism, and optimal swimming speed of a pelagic fish. J. Fish. Res. Bd. Can. 32(1): 33-41. doi:10.1139/f75-005.

Ware, D.M. 1978. Bioenergetics of Pelagic Fish: Theoretical change in swimming speed and ration with body size. J. Fish. Res. Bd. Can. 35(2): 220-228. doi:10.1139/f78-036.

Weisberg, S., Spangler, G., and Richmond, L.S. 2010. Mixed effects models for fish growth. Can. J. Fish. Aquat. Sci. 67(2): 269-277. doi:10.1139/F09-181.

Wickham, H., Averick, M., Bryan, J., Chang, W., McGowan, L.D.A., François, R., et al. 2019. Welcome to the Tidyverse. J. Open Source Softw. 4(43): 1686. doi:10.21105/joss.01686.

Wright, P.J., Metcalfe, N.B., and Thorpe, J.E. 1990. Otolith and somatic growth rates in Atlantic salmon parr, Salmo salar L: evidence against coupling. J. Fish Biol. 36(2): 241-249. doi:10.1111/j.1095-8649.1990.tb05599.x.

Zimmermann, F., Heino, M., and Steinshamn, S.I. 2011. Does size matter? A bioeconomic perspective on optimal harvesting when price is size-dependent. Can. J. Fish. Aquat. Sci. 68(9): 1651-1659. doi:10.1139/f2011-093.

Zimmermann, F., Ricard, D., and Heino, M. 2018. Density regulation in Northeast Atlantic fish populations: density dependence is stronger in recruitment than in somatic growth. J. Anim. Ecol. 87(3): 672-681. doi:10.1111/1365-2656. 12800. PMID:29380364.

Zimmermann, F., Claireaux, M., and Enberg, K. 2019. Common trends in recruitment dynamics of north-east Atlantic fish stocks and their links to environment, ecology and management. Fish Fish. 20(3): 518-536. doi:10.1111/ faf.12360. 